WE investigated the effect of ferulic acid (FA) and isoferulic acid (IFA), which are the main active components of the rhizoma of Cimicifuga beracleifolia $(\mathrm{CH})$, an anti-inflammatory drug used frequently in Japanese traditional medicine, on the production of macrophage inflammatory protein-2 (MIR-2) in a murine macrophage cell line, RAW264.7, in response to respiratory syncytial virus (RSV) infection. Follow ing the exposure of cells to RSV for $20 \mathrm{~h}$, the MIP-2 level in condition medium was increased to about $20 \mathrm{ng} / \mathrm{ml}$, although this level in mock-infected cells was negligible. In the presence of either FA or IFA, RSV-infected cells reduced MIP-2 production in a dose-dependent manner. These data suggest that FA and IFA might be responsible, at least in part, for the anti-inflammatory drug effect of $\mathrm{CH}$ ex tract th rough the inhibition of MIP-2 production.

Key words: Respiratory syncitial virus, Murine macrophage inflammatory protein-2, Ferulic and isoferulic acids, RAW264.7 cells

\section{Inhibitory effect of ferulic acid and isoferulic acid on the production of macrophage inflammatory protein-2 in response to respiratory syncytial virus infection in RAW264.7 cells}

\author{
S. Sakai, ${ }^{1}$ H. Kawamata, ${ }^{1}$ T. Kogure, ${ }^{1}$ N. Mantani, ${ }^{1}$ \\ K. Terasawa, ${ }^{1}$ M. Umatake ${ }^{2}$ and $\mathrm{H}$. Ochiai ${ }^{2, c A}$
}

Departments of ${ }^{1}$ Japanese Oriental Medicine and ${ }^{2}$ Human Sciences, Faculty of Medicine, Toyama Medical and Pharmaceutical University, Sugitani 2630, Toyama 930-0194, Japan

${ }^{\mathrm{CA} C o r r e s p o n d i n g}$ author
Tel.: $(+81) 764342281$, ext. 2415
Fax: (+81) 764345186
Email: ochai@ms.toyama-mpu.ac.jp

\section{Introduction}

Respiratory syncytial virus (RSV) is the major cause of acute lower respiratory tract illnesses such as bronchiolitis and pneumonia in infants and young children, and can cause severe, even fatal, infections in the elderly. ${ }^{1}$ Several studies have indicated that RSV is released initially from upper respiratory tract infections and then reaches the bronchoalveolar region, where viruses induce inflammation of the airway epithelium accompanied by peribronchiolar infiltrations of neutrophils. ${ }^{1,2}$ It is well known that neutrophil accumulation is an important characteristic of inflammation and modulates various inflammatory reactions. ${ }^{3}$ Since the initial discovery of interleukin- 8 as a novel neutrophil chemotactic cytokine, ${ }^{4-6}$ it has since been named a chemokine and been found in the conditioned medium (CM) of various cells in response to stimulation with lipopolysaccharide (LPS) as well as several virus infections. We previously reported that RSV infection strongly induces the production of macrophage inflammatory protein-2 (MIP-2), a murine counterpart of chemokine family, ${ }^{7}$ in RAW 264.7 cells. $^{8,9}$

On the other hand, the rhizoma of Cimicifuga sp., such as Cimicifuga heracleifolia $(\mathrm{CH})$ Komarov and Cimicifuga daburica Maxim are used frequently as antipyretic, analgesic and anti-inflammatory drugs in Japanese traditional medicine. Ferulic acid (FA), 3-(4-hydroxy-3-methoxyphenyl)-2-propenic acid and its isomer isoferulic acid (IFA), 3-(3-hydroxy4-methoxyphenyl)-2-propenic, have been recently recognized as the main active components of $\mathrm{CH}$ extract in the inflammation model in rats. ${ }^{10}$

In the light of these findings, we examined whether FA and IFA show inhibitory effects on MIP-2 production in response to RSV infection.

\section{Materials and methods}

\section{Preparation of drugs}

FA and IFA, purchased from Carl Roth GmbH (Karlsruhe, Germany), were freshly prepared in serum-free Dulbecco's modified Eagle's minimal essential medium (DMEM) at a concentration of $5 \mathrm{mM}$. The dissolved drugs were strilized through a Millipore filter before use.

\section{Cell}

A murine macrophage cell line, RAW264.7, was obtained from American Type Culture Collection and maintained in culture with DMEM supple mented with $10 \%$ fetal bovine serum (FBS), in a humidified atmosphere containing $5 \% \mathrm{CO}_{2}$ at $37^{\circ} \mathrm{C}$. Hep-2 cells were cultured in MEM supplemented with $10 \%$ of FBS in the same manner as above. 


\section{Virus}

RSV A2 strain, which was kindly supplied by Dr Watanabe (Rational Drug Design Laboratories, Fukushima, Japan), was propagated in a confluent monolayer of Hep-2 cells in a maintenance medium (MEM supplemented with 2\% FBS). ${ }^{1}$ When the cytopathic effect reached $80 \%$, the cultures were processed with three cycles of freezing and thawing. After centrifugation at $2000 \times g$ for $10 \mathrm{~min}$, the culture supernatant was collected and stored in a small portion at $-84^{\circ} \mathrm{C}$ as a virus stock solution. Virus titers were determined as plaque-forming units (PFU) on Hep-2 cells as described previously. ${ }^{1}$

\section{RSV infection}

RAW 264.7 cells were inoculated into a 96-well microplate at a density of $1 \times 10^{5}$ cells/well and cultured overnight at $37^{\circ} \mathrm{C}$. Thereafter, the cells were washed once with serum-free media and exposed for $3 \mathrm{~h}$ at $37^{\circ} \mathrm{C}$ to $20 \mu \mathrm{l}$ of virus solution at a multiplicity of infection (MOI) of $3 \mathrm{PFU} /$ cell. After virus adsorption, $200 \mu \mathrm{l}$ of serum-free medium with or without drugs were added ( $0 \mathrm{~h}$ post-infection) and further cultured for additional time periods as indicated.

\section{MIP-2 assay}

MIP-2 levels in the CM were examined by antibodysandwich enzyme-linked immunosorbent assay (ELISA) in which rabbit unlabeled and biotinylated anti-murine MIP-2 antibodies were used as the capture and second-layer antibodies, respectively, as described previously. ${ }^{11}$ Purified MIP-2 was used for standardization of MIP-2 levels, and MIP-2 levels in experimental groups were expressed as percent of control culture, in which infected cells were cultured in the absence of drugs. For statistical analysis, three wells were used for each experimental point.

\section{Statistical analysis}

The results were expressed as mean \pm standard deviation (SD). The differences were examined by Bonferroni's least-significant difference test.

\section{Results and discussion}

In the control culture, MIP-2 levels in the CM increased to the level of $20.4 \pm 0.8 \mathrm{ng} / \mathrm{ml}$ until $20 \mathrm{~h}$ after infection in a time-dependent manner. In the uninfected cells, no significant production (less than $0.5 \mathrm{ng} / \mathrm{ml}$ ) was observed throughout the experiments (data not shown). When the infected cells were cultured in the presence of FA and IFA, these

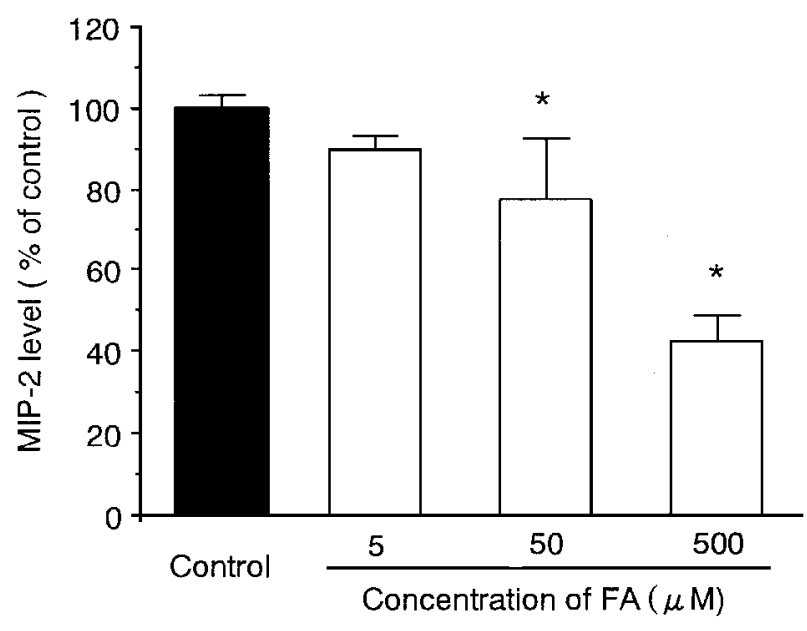

FIG. 1. Inhibitory effect of FA on MIP-2 production in RAW264.7 cells in response to RSV infection. RAW264.7 cells were infected with RSV at an $\mathrm{MOI}$ of $3 \mathrm{PFU} / \mathrm{cell}$. After absorption for $1 \mathrm{~h}$, the cells were cultured in the presence of FA at the indicated concentrations (open bar). The MIP-2 levels in 20-h conditioned media were determined and expressed as MIP-2 level by percent of control cultured in the absence of drugs (closed bar). Asterisks indicate a significant difference from control with a $P$ value of $<0.05$. Data are shown as the mean (thick bar)-SD (thin bar) of three determinations.

drugs showed inhibitory effects on MIP-2 production in a dose-dependent manner. At $20 \mathrm{~h}$, FA reduced MIP-2 levels to 74.4 and $42.8 \%$ of control at doses of 50 and $500 \mu \mathrm{M}$, respectively (Fig. 1). In addition, IFA also reduced MIP-2 levels to $61.8,58.0$ and $35.6 \%$ of control at doses of 5,50 and $500 \mu \mathrm{M}$, respectively (Fig. 2). These values were significantly

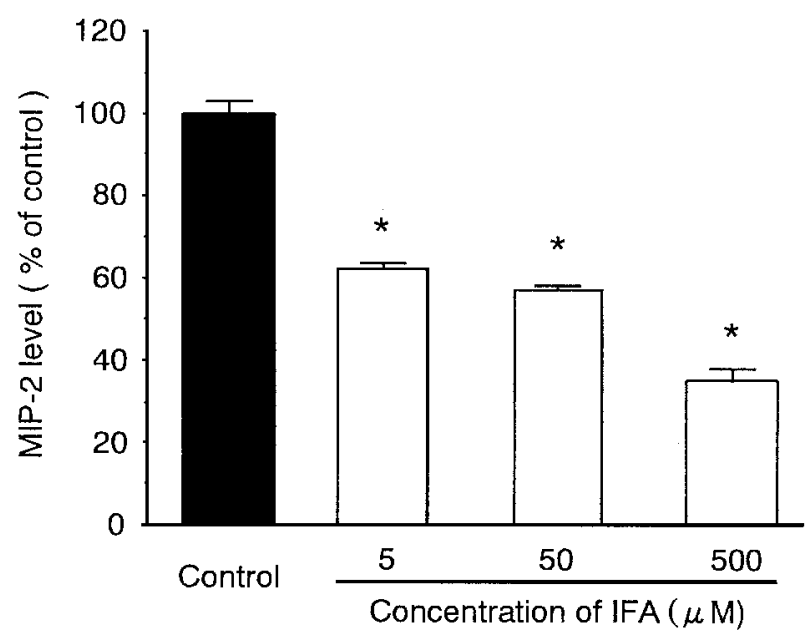

FIG. 2. Inhibitory effect of IFA on MIP-2 production in RAW264.7 cells in response to RSV infection. RAW264.7 cells were infected with RSV by the same manner as described in the legend for Fig. 1. After absorption for $1 \mathrm{~h}$, the cells were cultured in the presence of IFA at the indicated concentrations (open bar). The MIP-2 levels in 20-h conditioned media were determined and expressed as MIP-2 level by percent of control cultured in the absence of drugs (closed bar). Asterisks indicate a significant difference from control with a $P$ value of $<0.05$. Data are shown as the mean (thick bar)-SD (thin bar) of three determinations. 
lower than that of the control. At the highest dose $(500 \mu \mathrm{M})$, both FA and IFA reduced MIP-2 levels to 42.8 and $35.6 \%$ of the control, respectively. In contrast to FA, IFA exhibited a significant inhibitory effect even at the lowest dose $(5 \mu \mathrm{M})$. The cytotoxic effect of FA or IFA treatment at $500 \mu \mathrm{M}$ for $24 \mathrm{~h}$ could be ruled out by Trypan blue exclusion test, that is, FA- or IFA-treated cells were viable at more than $95 \%$ which was comparable to drug-untreated cells.

In Japanese oriental medicines, the rhizoma of $\mathrm{CH}$ are used frequently as antipyretic, analgesic and antiinflammatory drugs, and FA and IFA have been recently recognized as the main active components of $\mathrm{CH}$ extract in the inflammation model in rats. ${ }^{10}$ However, the mechanisms of anti-inflammatory effect of FA and IFA are not understood completely. In addition to a previous report indicating that FA inhibits MIP-2 production in response to LPS stimulation in RAW264.7 cells, ${ }^{12}$ this study confirmed that both FA and IFA inhibit MIP-2 production even in response to RSV infection in RAW264.7 cells in a dose-dependent manner. Since peribronchiolar infiltrations of neutrophils are important pathogenesis in RSV infections, ${ }^{13,14}$ MIP-2-inducing activity of RSV should play a key role. Taking into account the fact that neutrophils can cause tissue injuries, such as lung damage in adult respiratory distress syndrome and other inflammatory diseases, through the production of superoxide or some enzymes, in addition to killing ingested or invading microbes, ${ }^{15-17}$ these data suggest that FA and IFA might contribute at least in part to the anti-inflammatory drug effect of $\mathrm{CH}$ extract through the reduction of MIP-2 levels, and thereby the reduction of neutrophil infiltration into the inflammatory sites. In addition, the use of FA and IFA or $\mathrm{CH}$ ex tract seems to be a novel and attractive strategy for control of pneumonia induced by certain virus infections, including RSV infection.

\section{References}

1. Franke-Ullmann G, Pfortner C, Walter P, Ste inmuller C, Lohmann-Matthes ML, Kobzik L, Freihorst J. Alteration of pulmonary macrophage function by respiratory syncytial virus infection in vitro. J Im munol 1995; 154: 268-280.

2. Becker S, Quay J, Soukup J. Cytokine (tumor necrosis factor, IL-6, and IL-8) production by respiratory syncytial virus-infected human alveolar macrophages. JIm munol 1991; 147: 4307-4312.

3. Gallin JI, Wright DG. Role of secretory events in modulating human neutrophil chemotax is. JClin Invest 1987; 62: 1364-1374.

4. Yoshimura T, Matsushima K, Oppenheim JJ, Leonard EJ. Neutrophil chemotactic factor produced by lipopolysaccharide (LPS)-stimulated human blood mononuclear leukocytes: partial characterization and separation from interle ukin-1 (IL-1). J Im mu nol 1987; 139: 788-793.

5. Yoshimura T, Matsushima K, Oppenheim JJ, Leonard EJ. Purification of a human monocyte-derived neutrophil chemotactic factor has peptide sequence similarity to other host defence cytokines. Proc Natl Acad Sci USA 1987; 84: 9233-9237.

6. Harada A, Mukaida N, Matsushima K. Interleukin 8 as a novel target for intervention therapy in acute inflammatory diseases. Mol Med Today 1996; 11: 482-489.

7. Driscoll KE. Macrophage inflammatory proteins: biology and role in pulmonary inflammation. Exp Lung Res 1994; 20: 473-490.

8. Ochiai H, Sakai S, Nakajima K, Sakai T, Terasawa K. Inducing activity of respiratory syncytial virus on the production of macrophage inflammatory protein-2 in murine macrophages and airw ay lining cells. Acta Med Biol 1996; 44: 135-140.

9. Sakai S, Ochiai H, Kaw amata H, Kogure T, et al. Contribution of tumor necrosis factor $\alpha$ and interleukin- $1 \alpha$ on the production of macrophage inflammatory protein- 2 in response to respiratory syncytialvirus infection in a murine macrophage cell line, RAW264.7. J Med Virol 1997; 53: $145-149$.

10. ShiotaniY, Terasaw a K, Miyashiro H, et al. Studies on the anti-inflammatory effects of Chinese crude drug 'Shoma' (Cimicifugae Rhizoma). J Med Pharm Soc Wakan-Yaku 1993; 10: 110-117.

11. Ochiai H, Sakai S, Kogure T, Hirabayashi T, Nakajima K, Terasawa K. Development and some applications of enzyme-linked immunosorbent assay system for murine macrophage inflammatory protein-2 (MIP-2). Mediators Inflam mation 1996; 5: 206-209.

12. Sakai S, Ochiai H, Nakajima K, Te rasaw a K. Inhibitory effect of ferulic acid on macrophage inflammatory protein- 2 production in a murine macrophage cell line, RAW 264.7. Cy tokine 1997; 9: 242-248.

13. Everard ML, Sw arbrickA, Wrightham M, et a l. Analys is of cells obtained by bronchial lavage of infants with respiratory syncytial virus infection. Arch Dis Child 1994; 71: 428-432.

14. Faden H, Hong JJ, Ogra PL. Interaction of polymorphonuclear leukocytes and viruses in humans : adherence of polymorphonuclear leukocytes to respiratory syncytial virus-infected cells.J Virol 1984; 52: 16-23.

15. Robert MT, John ER. Neutrophils and adult respiratory distress syndrome. Am Rev Respir Dis 1983; 128: 552-559.

16. Blake DR, Hall ND, Bacon PA, et al. Effect of a specific iron chelating agent on animal models of inflammation. Ann Rheum Dis 1983; 42: 89-93.

17. Oda T, Akaike T, Hamamo to T, Suzuki F, Hirano T, Maeda H. Oxygen radicals in influenza-induced pathogenesis and treatment with pyran polymerconjugated SOD. Science 1989; 244: 974-976.

\section{Received 26 March 1999 accepted 6 April 1999}




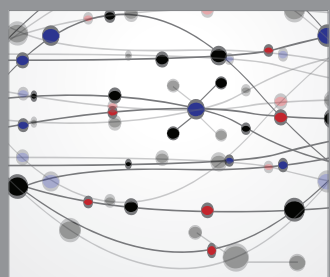

The Scientific World Journal
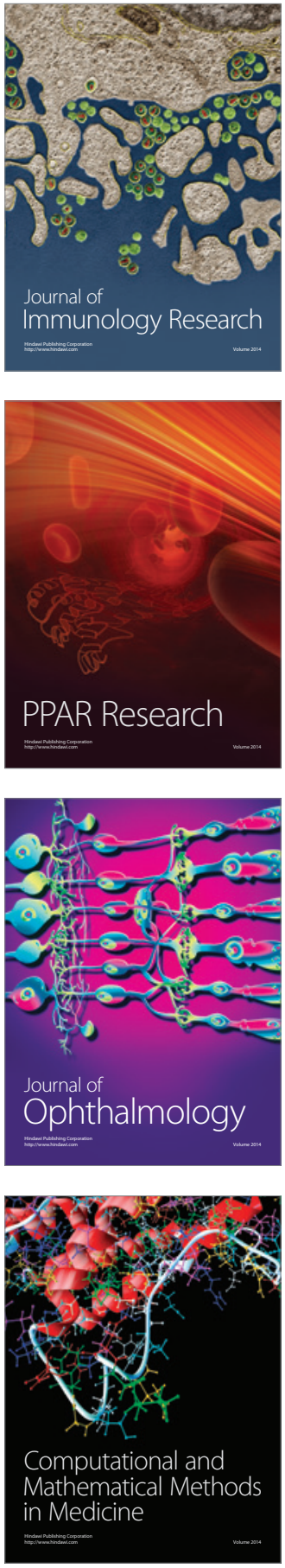

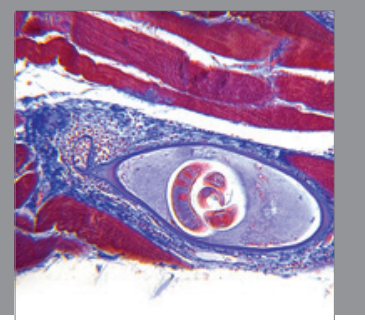

Gastroenterology

Research and Practice
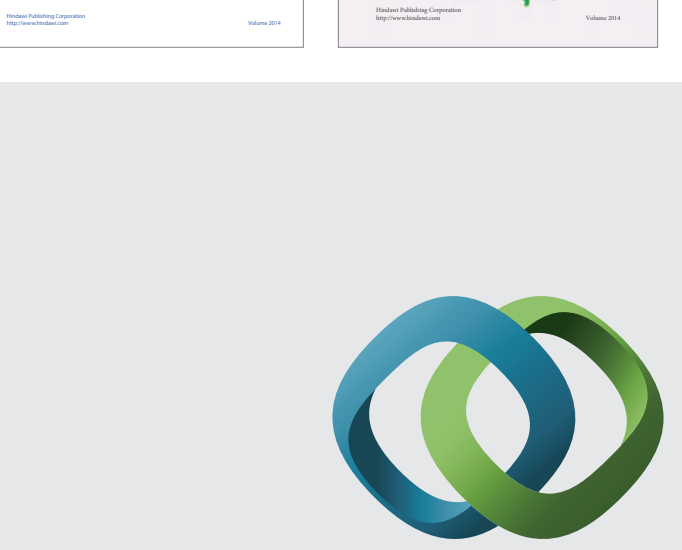

\section{Hindawi}

Submit your manuscripts at

http://www.hindawi.com
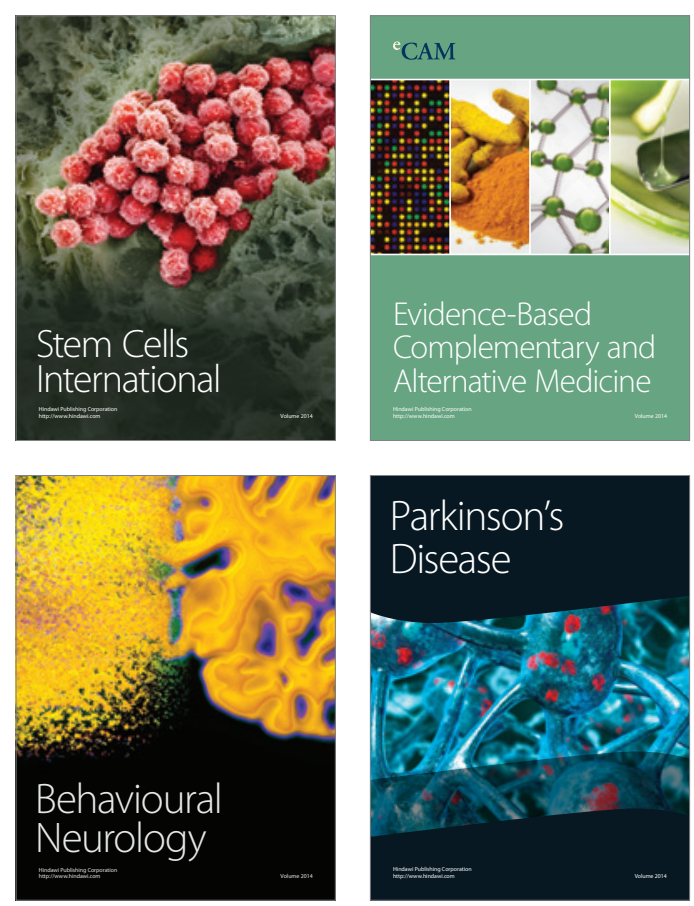

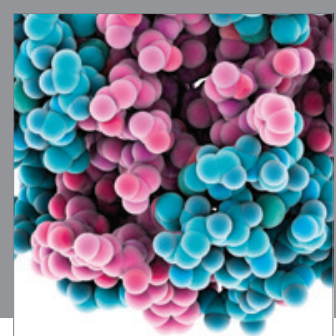

Journal of
Diabetes Research

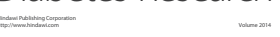

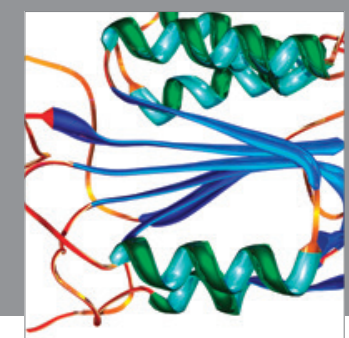

Disease Markers
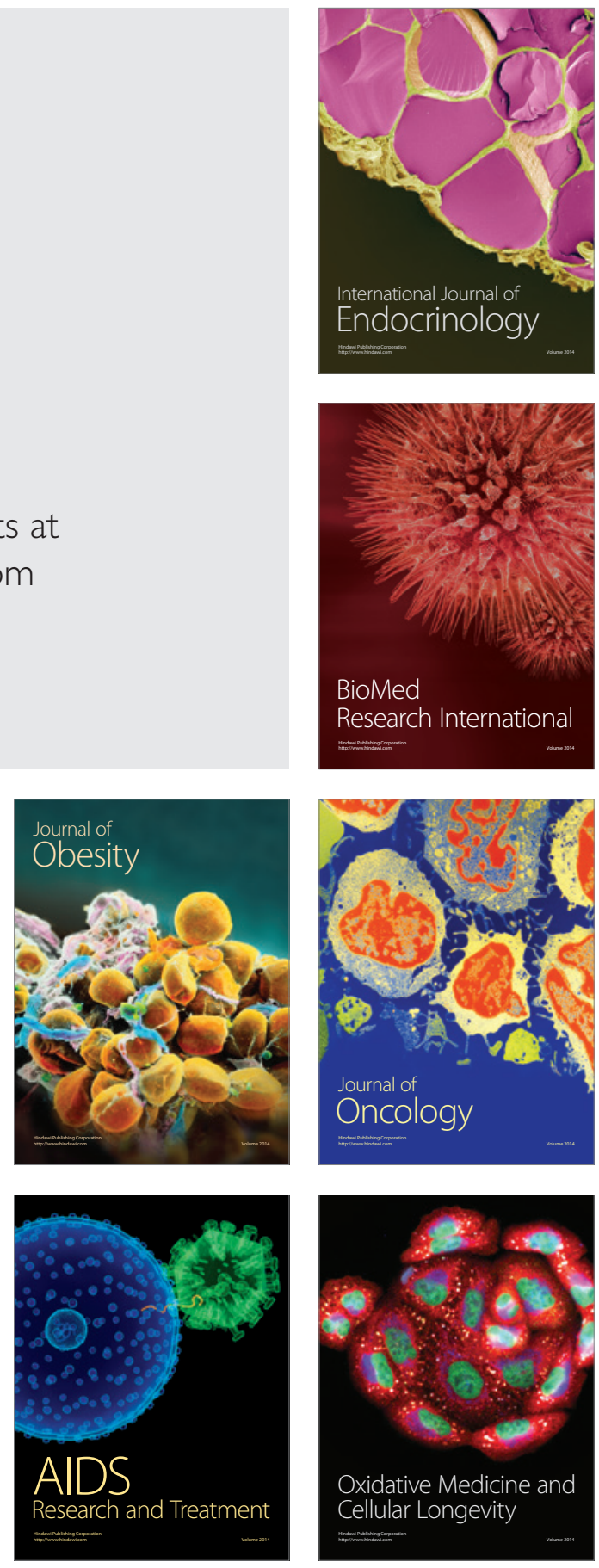